\title{
Eliciting Value-Judgments in Health Technology Assessment: An Applied Ethics Decision Making Paradigm
}

\author{
Georges-Auguste Legault1,2, Suzanne K.-Bédard ${ }^{2,3}$, Jean-Pierre Béland ${ }^{2,4}$, Christian A. Bellemare ${ }^{2,3}$, \\ Louise Bernier1,2, Pierre Dagenais5, Charles-Étienne Daniel1,2, Hubert Gagnon², \\ Monelle Parent ${ }^{2}$, Johane Patenaude ${ }^{2,5^{*}}$
}

${ }^{1}$ Faculté de droit, Université de Sherbrooke, Sherbrooke, Canada

${ }^{2}$ Institut interdisciplinaire d'innovation technologique (3IT) de l'Université de Sherbrooke, Sherbrooke, Canada

${ }^{3}$ Centre intégré universitaire de santé et services sociaux (CIUSSS) de l'Estrie-Centre hospitalier de l'université de Sherbrooke (CHUS), Faculté de médecine et des sciences de la santé de l'Université de Sherbrooke, Sherbrooke, Canada

${ }^{4}$ Unité d'enseignement en éthique, Département des sciences humaines, Université du Québec à Chicoutimi (UQAC), Chicoutimi, Canada

${ }^{5}$ Faculté de médecine et des sciences de la santé, Université de Sherbrooke, Sherbrooke, Canada

Email: Georges-Auguste.Legault@USherbrooke.ca, Pierre.Dagenais@USherbrooke.ca, Christian.Bellemare@USherbrooke.ca, suzanne.kocsis-bedard.ciussse-chus@ssss.gouv.qc.ca, jpbeland@uqac.ca, Louise.Bernier@USherbrooke.ca,

Charles-Etienne.Daniel@USherbrooke.ca, hubert.gagnon@usherbrooke.ca, Monelle.Parent@USherbrooke.ca,

*Johane.Patenaude@USherbrooke.ca

How to cite this paper: Legault, G.-A., K.-Bédard, S., Béland, J.-P., Bellemare, C. A., Bernier, L., Dagenais, P., Daniel, C.-É., Gagnon, H., Parent, M., \& Patenaude, J. (2021). Eliciting Value-Judgments in Health Technology Assessment: An Applied Ethics Decision Making Paradigm. Open Journal of Philosophy, 11, 307-325.

https://doi.org/10.4236/ojpp.2021.112021

Received: March 31, 2021

Accepted: May 11, 2021

Published: May 14, 2021

Copyright $\odot 2021$ by author(s) and Scientific Research Publishing Inc. This work is licensed under the Creative Commons Attribution International License (CC BY 4.0).

http://creativecommons.org/licenses/by/4.0/

(c) (i) Open Access

\begin{abstract}
The worldwide COVID-19 pandemic has shed more light on the difficulty of making health care decisions integrating scientific knowledge and values associated to life and death issues, human suffering, quality of life, economic losses, liberty of movement, etc. But the difficulties related to health care decisions and the use of innovative drugs or technologies are not new, and many countries have created agencies that have the mandate to evaluate new technologies in health care. Health Technological Assessment (HTA) reports' aim is to guide the decision makers in these difficult matters. There are two ethical components in HTA. The first is the report's presentation of an ethical evaluation of the technology. The second is the value-ladenness of the HTA decision-making process itself. When implicit value judgments are not elicited, the justification of the final decision cannot be transparent. The present paper aims to identify and elicit the implicit value-judgments related to each step of the HTA process. This research is grounded on an applied ethics decision-making paradigm based on the role of value judgments in the decision-making process. The first part discusses two different approaches to values and value judgments in HTA. In the second part, citations mentioning
\end{abstract}


value judgments extracted from a systematic review on the integration of ethics into HTA were categorized to elicit the value judgments and their criteria for each different HTA decision-making steps. The results show that there are 18 decision-making steps in the HTA process where 23 implicit value-judgments can be recognized. The range of these value judgments encompasses the whole HTA process: from the initial request, the presenting of the principal issues, to the final report's dissemination. Since stakeholders need to understand which value judgments the conclusion of a report relies on, eliciting the implicit value judgments in the HTA decision-making process should yield more transparency.

\section{Keywords}

Applied Ethics, Health Technology Assessment, Decision-Making Paradigm, Value Judgments, Values

\section{Background}

The worldwide COVID-19 pandemic has shed more light on the difficulty of making health care decisions integrating scientific knowledge and values associated to life and death issues, human suffering, quality of life, economic losses, liberty of movement, etc. But the difficulties related to health care decisions and the use of innovative drugs or technologies are not new, and many countries have created agencies that have the mandate to evaluate new technologies in health care. The World Health Organisation defines health technology assessment as follows: "Health technology assessment (HTA) refers to the systematic evaluation of properties, effects, and/or impacts of health technology. It is a multidisciplinary process to evaluate the social, economic, organizational and ethical issues of a health intervention or health technology. The main purpose of conducting an assessment is to inform policy decision-making." (WHO-HTA, 2017).

The value-ladenness of the HTA process has been widely recognized in the HTA literature for different reasons (Burls et al., 2011; DeJean et al., 2009; Duthie \& Bond, 2011; Hofmann, 2008; Reuzel et al., 2004; Saarni et al., 2011; ten Have, 2004), all of which converge on their fundamental role in decision-making. Considering that the essential goal of HTA is to improve health care, the main objective of HTA reports, according to some authors (Hofmann, 2008; Saarni et al., 2011, 2008), is to elicit the reasons grounding the final decisions in health care. From an applied ethics perspective, grounding reasons for these decisions are not only facts but also values. The quality of health care for a population can be considered as the fundamental value guiding the decision maker. How can HTA reports accomplish their social mission in order to guide decision makers in health care? For many authors (Hofmann et al., 2018; Sandman \& Heintz, 2014; ten Have, 2004) there are two phases in HTA reports: the assessment phase where scientific data is gathered on efficacy, safety and costs, and the appraisal phase of the data where contextual considerations are consi- 
dered and recommendations proposed. According to these authors, the value-ladenness can only be found in the appraisal phase of a health technology process since this phase is intertwined with values, whereas the assessment phase solely rests on facts. The classical distinction between fact and value judgments governs unconsciously the entire process of HTA (Legault, K.-Bédard, Bellemare et al., 2018). Other authors have clearly demonstrated that all of the steps in the HTA process are grounded on value judgments (Hofmann et al., 2015, 2018; Saarni et al., 2011). In 2005, the INAHTA addressed the question of the necessity to elicit these value judgments in HTA reports to its Ethics Working Group (INAHTA, 2005). Even if there are implicit value judgments in HTA, should HTA reports elicit these implicit value judgments imbedded in the process? Does the decision maker need this elicitation to complete his decision-making process?

The debate on eliciting value judgments in the HTA process raises fundamental questions for philosophy: What is a value? What is a value judgment? What role do value judgments have in decision-making? How do factual judgments and value judgments merge in the decision-making process? Applied ethics has, from the very beginning, focused on decision-making. Medical ethics and bioethics were always concerned with the decision-making of doctors, nurses and other health professionals in complex clinical decisions. As Joseph Fletcher has shown at the initial establishment of applied ethics, decision-making is always contextual. What he named situational ethics can only be guided by value judgments based on reasons rather than deductive application of norms (Fletcher, 1966).

The conceptual analysis of values, value judgments and the decision-making paradigm is a prerequisite for a systematic analysis of the value judgments implied in the HTA decision-making process. Therefore, the first part of this paper will address the role of values and value judgments in the decision-making process. Our aim is to elicit the implicit decision-making paradigm implied in the HTA literature in order to compare it to an applied ethics approach derived from an ethical deliberation framework we developed for nanotechnologies ( $\mathrm{Pa}-$ tenaude et al., 2015). In the second part, we will operationalize the decision-making applied ethics parading and elicit the implicit value-judgments of the HTA decision-making process based on HTA practitioners' experience and the HTA literature on the subject.

\section{Conceptual Analysis of Values, Value Judgments and Decision-Making in HTA}

It is generally assumed that the aim of HTA reports is to help decision makers in their work. With this assumption in mind, we can consider that the HTA process is therefore guided by a decision-making paradigm. The traditional distinction of a two-phase process in HTA, consisting of assessment and appraisal sets a decision-making paradigm that considers two sets of data. Assessment of efficacy and safety are considered as facts and the factual judgments are grounded in experimental research principally controlled trial that give what is 
considered as context-free evidence. Economic analysis depends more on contextual considerations, but it still provides evidence based on facts, even if they are context-sensitive. In the HTA process the impacts of the technology is restricted to two domains: health and economics, the other impacts on people, professionals, organizations and society are not considered important data at this phase in the decision-making process. One way of explaining the importance given to efficacy, safety and economics in technology assessment is to consider that HTA has inherited from the distinction between environment, health and safety issues (EHSI) and ethical, legal and social issues (ELSI) in regulatory law. Regulatory laws cannot impose arbitrary constraints that would hinder the liberty of commerce. Only scientific evidence showing that there are serious impacts on environment, health or safety can justify imposing restrictions on production or distribution of the products (Bernier et al., 2020).

Introducing a health technology can have an impact on the rights of the citizens or on the ways people live, and this raises questions about their legal or moral acceptability. These concerns are the subject matter of the appraisal phase. Usually, at this phase, contextual considerations on the ethical, legal, organizational, professional and social impacts are deemed relevant. This decision-making paradigm reproduces the classical distinction between judgment of facts that are objective and value judgments that are subjective. A sound decision is based, therefore, on objective facts established by scientific research. Since science cannot appraise these facts based on "objective reasons" the contextual considerations in the HTA reports therefore inform the decision maker of certain impacts that he can only assess subjectively. If the decision-making paradigm was only based on factual data, this would be a rational decision-making process. If the technology is really efficient, safe and affordable, there should be no hesitation in adopting it. But if there is no conclusive evidence on efficiency, safety or affordability, then the decision should be postponed until the evidence is available. In real life situations, however, such conclusive evidence is not always available and decisions cannot wait until all the evidence is available.

In the HTA literature, philosophy is mainly referred to in the context of the ethical evaluation of a technology. Nine approaches have been identified as candidates for this ethical evaluation process (Legault et al., 2019). In most of the approaches normative models are applied to a specific technology and the relationship of facts to value is one of conformity. In other words, do the facts show a breach of a norm.

Value-ladenness of the HTA process opens another philosophical area, focused on the relationship of facts and values in action. Unfortunately, there are very few articles on the fact-value dichotomy in decision-making or on the relationship of fact and values in the HTA decision-making process.

In their analysis of the fact-value relationship in HTA, Hofmann, Bond and Sandman (Hofmann et al., 2018) qualify this relationship as one of "evaluating facts and facting evaluations". Different aspects of evaluating facts are highlighted. The first example is relative to the positivistic approach where facts are 
pure facts and have no relation to values. This approach is the background for the distinction between two forms of evidence in HTA: context-free evidence and context-sensitive evidence. The first has more value for a positivist than the other because it is based on "objectivity". In other words, contextual analysis corrupts the objectivity of science. Another example is the process of HTA itself, "from selecting a technology for assessment and deciding on end points, population, and comparator, as well as selecting economic models and how to present the results, are strongly value dependent" (Hofmann et al., 2018). In other words, the methodological decisions made in the scientific assessment are related to values.

To show this value dependence the authors present 7 different categories of values involved in HTA with corresponding associated values (Hofmann et al., 2018). Six categories of values are listed: Decision making values, Values in HTA, Value of HTA, Professional values, Social values, Person-related values and Basic Human values. This analysis sets out the value dependence of all parts of HTA and its value-ladenness by associating different values to aspects of the process, but there is no specific analysis of the relation between the steps of the HTA process and the values listed.

When analyzing the aspect of "facting evaluations", the authors refer to the role of society in constructing values (Hofmann et al., 2018). The social construction of values is imbedded in technology and technological development, as well as in social agencies making technological assessments. Furthermore, discussion on values in HTA with stakeholders' involvement is an alternative route to socially construct evaluations of a technology.

Analysing their philosophical contribution to the fact-value relationship, the authors first refer to David Hume's law stating that you cannot infer from facts what should be done (Hofmann et al., 2018). In other words, “(...) a fact always needs to be complemented by a number of value assumptions to work as action guiding." This is the only reference to the relationship between value assumptions and action. But the question of how value assumptions guide action is not analysed. As their table on values in HTA implicitly suggests, the distinction between instrumental and intrinsic values could help clarify the role of values in HTA. But there is no discussion on what the intrinsic values are and how exactly they play a role in HTA. In their philosophical considerations, values are associated to the different goals and "the awareness of various goals makes it possible to identify potential conflicting values" (Hofmann et al., 2018). Finally, the authors reject both the positivist and social constructivist conception of values as mere personal or social preferences. "They are part of a process of framing the relationship between our goals and aspirations and various constraints. How rational this process is, depends on how well we are to assess the relation between facts and values." One major contribution of this analysis is to recognize that fact and values are socially intertwined in social practices, be it HTA agencies, social, professional or personal practices. Values are associated to the goals we seek in our practices and these goals connote what we aspire to. The aspirational 
dimension of values is not considered to be a personal or social preference because the process of values and action refers to reasons, but such relation is not specified. This approach is concentrated on values, but it does not take into consideration the nature and role of value judgments in the decision-making process.

Another way of thinking the relationship of fact-value in HTA is to imbed this relationship in an applied ethics decision-making paradigm. The distinction between rational and reasonable made by Perelman (Perelman, 1979) proposes a new path, which acknowledges the place of reason in decision-making. Deductive logic lies in the sphere of the rational while the reasonable one applies to decision-making. A reasonable decision takes into account the compromises necessary to be applicable in concrete situations. Therefore, a reasonable decision is based on facts and values that are intertwined in the decision process. An applied ethics' deliberative model proposed for professional decision-making (Legault, 1999) and for responsible innovation (Legault, Verchères, \& Patenaude, 2018) considers the decision-making process in 4 steps (Figure 1). The first step consists of making an impact analysis of the intended action and so considers both the impacts of doing and not doing the action on all stakeholders. An impact analysis is based on the causal connexion between the action and the impacts on all stakeholders. Three sets of data are required: the first is the identification of the nature of the impact's connexion, the second the knowledge that grounds the alleged connexion and the third, the probability that the impact will indeed take place. Applied to HTA, such impact analysis does not discriminate between the impacts: efficacy, safety, cost, ethical, legal, organizational and

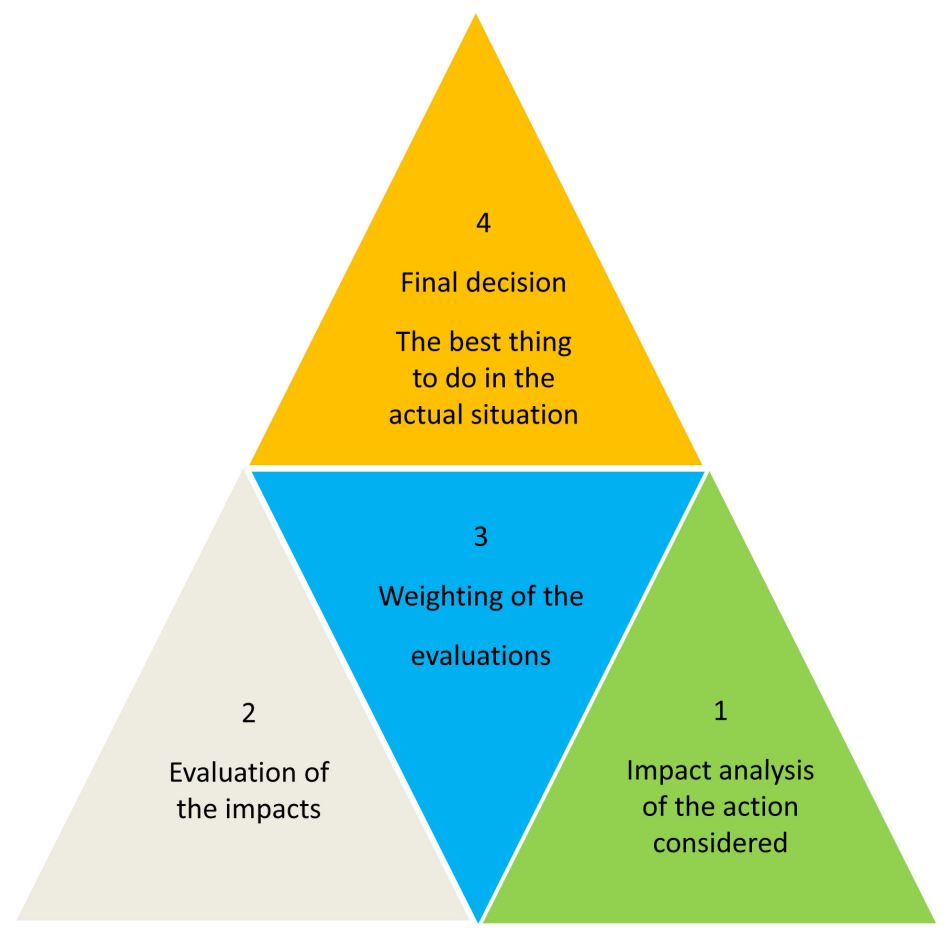

Figure 1. Four steps process proposed for professional decision making and responsible innovation. 
professional impacts are thus all as important. The three sets of data must be generated for each impact without having an implicit priority setting on scientific data over other data. The second step consists of the evaluation of the impacts. Impact analysis is not value-free because impacts are either positive or negative. Eliciting the implicit value of the impact under consideration determines the referential value for the evaluation (value judgment). For example, the impact of a drug as a treatment for a disease would aim at establishing if there is a causal relationship between them, and if so, what is exactly the impact on the disease. But this drug will have side effects that have to be analysed. The two implicit values are "efficacy" and "safety". For many HTA professionals, efficacy and safety are considered in HTA as factual judgments and not value judgments. From a speech act approach, factual judgments and value judgments differ mainly on one characteristic, factual judgments are binary (true or false), whereas value judgments are incremental judgments (more or less) (Legault, K.-Bédard, Bellemare et al., 2018). Saying that a drug is effective or safe is therefore a value judgment, based on certain criteria utilized to evaluate its effectiveness or safety. The evaluation consists of identifying at first the referential value, then the choice of the criteria is made and their application to the facts is provided by the impact analysis. A drug may be more or less effective, or more or less safe. This is also true for all the values implied in the impact analysis. An impact analysis will always show positive and negative impacts on different stakeholders. This is often framed as a conflict of values. In a decision process, however, a conflict of values is a conflict between value judgments on the impacts considered. In such a situation, a priority setting of the value judgments to be considered is the only way to resolve such conflict. This is a value judgment on the value judgments that takes into consideration the specific characteristics of the evaluation (i.e. more or less) and the referential value for the quality of our living togetherness. In other words, the final decision is grounded on the reasons that can be given to show that the action considered is the best thing to do for all stakeholders in the actual situation.

In our applied ethics' decision-making process, facts and values are intertwined since the facts ground the value judgments that are central to the decision-making process and its justification to stakeholders. When applying this approach to the HTA decision-making process, implicit value judgments and their criteria can be elicited.

Moreover, it has been argued that all the parts of HTA, from selecting a technology for assessment and deciding on end points, population, and comparator, as well as selecting economic models and how to present the results, are strongly value dependent.

\section{Eliciting the Implicit Value Judgments of the HTA Decisional Process Based on HTA Practitioners' Experience and HTA Literature on the Subject}

Each step of the HTA process involves important decisions that do have impacts on the strength and limitations of the final report. The first task of our analysis 
was to identify the decisions involved in each step of the process and then clarify the structure of the implicit value judgments involved. Evaluations, as explained in the previous section, are not a description of something but rather the attribution of a quality to something. Saying that an apple is good (value) is not describing a quality of the apple but is rather attributing it such quality. Evaluations, like assertions, should be grounded on reasons, so on what grounds can we attribute the value of good to an apple? The reasons for attributing goodness to something depend on the criteria of that attribution. For example, an apple can be evaluated as having a positive effect on a person's health, such as stated in the proverb: "An apple a day keeps the doctor away". The criteria (i.e. the health benefit) operationalize the general value attribution by identifying the primary reason for such attribution, but this is not sufficient since a causal relationship must link the apple to the health of a person. This is why evaluations should be grounded on factual data. Many articles in the HTA literature have addressed the value-ladenness of the HTA process without a decision-making paradigm. The aim of our analysis is to show, based on the HTA literature, how a decision-making paradigm based on the structure of the value judgments could provide a better understanding of the value-ladenness of the HTA process. The following methodology explains how this analysis, entirely based on the HTA literature, demonstrates on how values are addressed in HTA process.

Quotes referring to value judgments were extracted from our systematic review on the integration of ethics into HTA (Bellemare et al., 2018) by two independent researchers. An initial identification of the main steps of the HTA process implying implicit value judgments was carried out and data on the nature of the given value judgment was collected. As there exists no standardized procedure for the HTA process due to the different types of mandates found throughout the various HTA agencies and countries around the world, we systematized the HTA decision steps according to the procedure implemented by our local hospital-based HTA unit (UETMISSS of CHUS, Sherbrooke, QC, Canada) with the participation of local HTA evaluators involved as co-investigators in this research (Bellemare et al., 2017). This procedure was itself inspired in part by the work of others (Busse et al., 2002; European Network for Health Technology Assessment (EUnetHTA), 2016; Kristensen \& Sigmund, 2007).

Data from the selected quotes were identified by the two independent researchers and recorded in a structured data collection sheet representing: 1) the different steps of decision-making in HTA, 2) the description of their inherent implicit value judgments (evaluation) made explicit, 3) the criteria that grounds the attribution of the value to the facts considered, and 4) references to the quotes found in the HTA literature. The results were discussed, modified and validated by the entire research team including local HTA evaluators and a member of the Methodological Council of INESSS and, as a result, mapped into a table (Table 1).

Table 1 shows 18 steps in the HTA process, whereby 23 implicit value judgments (which were made explicit) can be observed. Of course, this table is a not 
Table 1. HTA process steps, their implicit value judgments made explicit and the eliciting criteria.

\begin{tabular}{|c|c|c|c|}
\hline HTA process steps & $\begin{array}{l}\text { Value Judgments Made Explicit } \\
\text { (Evaluations) }\end{array}$ & Criteria & References \\
\hline $\begin{array}{l}\text { 1. Agency's Official Mandate } \\
\text { (scientific expectations, ethical } \\
\text { analysis, assessment \& appraisal) }\end{array}$ & $\begin{array}{l}\text { Relevance of deliverables for } \\
\text { decision-making. }\end{array}$ & $\begin{array}{l}\text { Health care. } \\
\text { Health expenditures. }\end{array}$ & $\begin{array}{l}\text { (European Network for Health } \\
\text { Technology Assessment } \\
\text { (EUnetHTA), 2016; Hofmann, 2013) }\end{array}$ \\
\hline 2. Analysis of HTA request & Possible conflict of interest. & $\begin{array}{l}\text { Interest from initiator of the } \\
\text { report. }\end{array}$ & $\begin{array}{l}\text { (Busse et al., 2002; European } \\
\text { Network for Health Technology } \\
\text { Assessment (EUnetHTA), 2016) }\end{array}$ \\
\hline 3. Evaluation of HTA Request & Relevance of the request. & $\begin{array}{l}\text { Relevance of research questions } \\
\text { addressing the impacts of the } \\
\text { technology. } \\
\text { Overall costs of HTA. }\end{array}$ & $\begin{array}{l}\text { (Busse et al., 2002; European } \\
\text { Network for Health Technology } \\
\text { Assessment (EUnetHTA), 2016; } \\
\text { Hofmann, 2013; Strech \& } \\
\text { Tilburt, 2008) }\end{array}$ \\
\hline 4. Priority Setting for requests & Importance of the request. & Urgency. & $\begin{array}{l}\text { (Hofmann, 2013; } \\
\text { Hofmann et al., 2014a, 2014b) }\end{array}$ \\
\hline $\begin{array}{l}\text { 5. Scoping } \\
\text { a) Strategic Analysis } \\
\text { (Choice of parties involved in } \\
\text { the scoping process) } \\
\text { b) Preliminary Analysis }\end{array}$ & $\begin{array}{l}\text { Relevance of selected parties. } \\
\text { Relevance of selected issues. } \\
\text { Quality of information gathered } \\
\text { for the scoping. } \\
\text { Relevance of the choice of } \\
\text { comparator (Population, } \\
\text { Intervention, Comparator, } \\
\text { Outcome, Setting) } \\
\text { Weight of the information/results } \\
\text { to frame the research questions. }\end{array}$ & $\begin{array}{l}\text { Contribution to the process. } \\
\text { Relevance addressing the impacts } \\
\text { of the technology. } \\
\text { Idem. } \\
\text { Idem. } \\
\text { Idem. }\end{array}$ & $\begin{array}{l}\text { (Busse et al., 2002; European } \\
\text { Network for Health Technology } \\
\text { Assessment (EUnetHTA), 2016; } \\
\text { Hofmann, 2013; Hofmann et al., } \\
\text { 2014b; The National Institute for } \\
\text { Health and Care Excellence (NICE), } \\
\text { 2008) }\end{array}$ \\
\hline 6. Framing the Policy Question & $\begin{array}{l}\text { Importance of the action to be } \\
\text { considered by the decision makers. }\end{array}$ & Impact of such action. & (Busse et al., 2002) \\
\hline $\begin{array}{l}\text { 7. Framing the Research } \\
\text { Questions }\end{array}$ & $\begin{array}{l}\text { Importance of outcomes to } \\
\text { be/not to be considered. }\end{array}$ & $\begin{array}{l}\text { Relevance to agency's mandate } \\
\text { (1.). } \\
\text { Relevance to policy question (6.). } \\
\text { Relevance of technology's impact } \\
\text { analysis. }\end{array}$ & $\begin{array}{l}\text { (Busse et al., 2002; European } \\
\text { Network for Health Technology } \\
\text { Assessment (EUnetHTA), 2016; } \\
\text { Hofmann, 2013; Hofmann et al., } \\
\text { 2014b; Strech \& Tilburt, 2008) }\end{array}$ \\
\hline 8. Data Collection Strategy & $\begin{array}{l}\text { Importance of criteria and measure } \\
\text { procedures for each of the research } \\
\text { question's outcome. } \\
\text { Relevance of selected data bank. }\end{array}$ & $\begin{array}{l}\text { Relevant information. } \\
\text { Idem. }\end{array}$ & $\begin{array}{l}\text { (European Network for Health } \\
\text { Technology Assessment } \\
\text { (EUnetHTA), 2016; Hofmann, 2013; } \\
\text { Strech \& Tilburt, 2008) }\end{array}$ \\
\hline 9. Data Gathering & $\begin{array}{l}\text { Relevance of inclusion/exclusion } \\
\text { criteria. }\end{array}$ & Relevant information. & (Hofmann, 2013) \\
\hline $\begin{array}{l}\text { 10. Results and Evaluation of } \\
\text { Evidence }\end{array}$ & Quality of the evidence. & Validity of the information. & $\begin{array}{l}\text { (Hofmann et al., 2014a; } \\
\text { Strech \& Tilburt, 2008) }\end{array}$ \\
\hline $\begin{array}{l}\text { 11. Evidence Synthesis and } \\
\text { Results Presentation }\end{array}$ & $\begin{array}{l}\text { Importance of some } \\
\text { data/non-importance of other. }\end{array}$ & $\begin{array}{l}\text { Relevance to agency's mandate } \\
\text { (1.). } \\
\text { Relevance to policy question (6.). } \\
\text { Relevance to research question } \\
\text { (7.). }\end{array}$ & $\begin{array}{l}\text { (Busse et al., 2002; European } \\
\text { Network for Health Technology } \\
\text { Assessment (EUnetHTA), 2016; } \\
\text { Hofmann, 2013; } \\
\text { Hofmann et al., 2014b) }\end{array}$ \\
\hline 12. Discussion of Results & Relevance of the results discussed. & $\begin{array}{l}\text { Relevance to agency's mandate } \\
\text { (1.). } \\
\text { Relevance to policy question (6.). } \\
\text { Relevance to research question } \\
\text { (7.). }\end{array}$ & (Hofmann et al., 2014a) \\
\hline
\end{tabular}




\section{Continued}

\begin{tabular}{|c|c|c|c|}
\hline $\begin{array}{l}\text { 13. Discussion of the } \\
\text { Limits of the Report }\end{array}$ & Validity of the information retrieved. & $\begin{array}{l}\text { Strengths and limits of the } \\
\text { studies examined. }\end{array}$ & (Strech \& Tilburt, 2008) \\
\hline 14. Conclusion & $\begin{array}{l}\text { Importance of the elements selected } \\
\text { from the report answering the } \\
\text { research- and policy-questions. }\end{array}$ & $\begin{array}{l}\text { Relevance to research question } \\
\text { (7.). } \\
\text { Relevance to policy question (6.). }\end{array}$ & (Hofmann et al., 2014a) \\
\hline 15. Recommendations & $\begin{array}{l}\text { Importance of the considerations } \\
\text { justifying the recommendation. }\end{array}$ & $\begin{array}{l}\text { Weighting of diverging } \\
\text { evaluations. }\end{array}$ & $\begin{array}{l}\text { (Busse et al., 2002; Hofmann, 2013; } \\
\text { Rawlins, 2014; Strech \& } \\
\text { Tilburt, 2008) }\end{array}$ \\
\hline $\begin{array}{l}\text { 16. Choice of External } \\
\text { Reviewers }\end{array}$ & $\begin{array}{l}\text { Quality of the reviewers' } \\
\text { contribution to the final report. }\end{array}$ & Expertise. & (Hofmann, 2013) \\
\hline $\begin{array}{l}\text { 17. Integration of Reviewers' } \\
\text { Comments in the Report }\end{array}$ & $\begin{array}{l}\text { Importance of the comments to } \\
\text { the final report. }\end{array}$ & Relevance of such comments. & (Hofmann, 2013) \\
\hline 18. Dissemination & Importance of targeted audiences. & $\begin{array}{l}\text { Relevance of target audience to } \\
\text { decision-making. }\end{array}$ & (Hofmann, 2013) \\
\hline
\end{tabular}

exhaustive account of all the decisions made in the whole HTA process and it does not cover all value judgments, but it represents the fundamental decisions made where important value judgments are not explicitly addressed. The range of these value judgments that were elicited encompass the whole HTA process from the initial mandate of the agency presenting the decision-making issues to the dissemination of the final report. The criteria corresponding to each value judgment are also listed in Table 1. References to the published citations gathered for each category indicate the nature of the value judgments found in the HTA process.

HTA agencies throughout the world do not all have the same mandate and are not constituted by the same legal decree (Table 1 Step 1). For example, in the province of Québec (Canada), the HTA agency Institut national d'excellence en santé et services sociaux (INESSS) was established under a specific law requiring HTA to integrate both scientific and ethical analyses (Éditeur officiel du Québec, 2018). On the other hand, the Canadian Agency for Drugs and Technologies in Health (CADTH) was created based on an agreement between federal, provincial and territorial governments. Thus, the social and political decisions, taken when creating an HTA agency, implicitly carry the implicit value-judgment of the relevance of the information in the decision-making for the final report given their governance context. In order to judge the relevance of such information, two criteria are commonly used: relevance to the subject matter and relevance to the quality of the information. Information on the health impacts of a given drug or technology is required to support a well-guided decision. Therefore, clinical and toxicological impacts must be taken into consideration in the agencies' mandate. But is this information sufficient to support decision makers with appropriate guidance? Should other impacts such as: health expenditures, clinical practice, modifications in the workplace and other impacts on patients, be stipulated in the agencies' mandate in order to fulfill the agencies social role in 
guiding the decision makers? Assuming HTA agencies are governed by an evidence-based approach, this implies a priori a value judgment that considers that evidence grounded on rigorous scientific methodology is worthier to decision makers than non-scientific, contextual, considerations.

Implicit value judgments that are imbedded in the establishment of an HTA agency have an impact on the way the agency will analyze any submitted request (Table 1 Steps 2, 3 and 4). A given agency might consider that each submitted request must be treated exactly the way the request was prepared. In other words, such an agency may not have the power to question a submitted request. Other agencies may analyze the request in order to clarify, for example, if there are conflicts of interest or if the request is relevant to their mandate and, in some cases, if they can prioritize a request.

The scoping (Table 1 Step 5) determines the outcome of the HTA process, and the value judgments (implicit or explicit) made at this step will be imbedded in future HTA steps. When the scoping step is formalized into a procedure, such as involving an advisory committee, the first decision to be made is the selection of committee members. Here again, aside from the possible conflict of interest, the choice of a member (a party) reflects an implicit value judgment on the relevance and weight of this committee members' point of view, and thus on the quality of information to be gathered in a scoping process. For instance, to decide whether a patient should already be a member of a committee at the scoping step requires an analysis of the type of information this patient would bring to the discussion and how other committee members would judge the relevance of such point of view to the scoping process. Each committee member will have a viewpoint on what type of impacts should be considered in the HTA process. Taking into consideration the value of such different standpoints will influence all the decisions made during the primary analysis for the HTA.

Drugs and technologies may have multiple impacts on health, health expenditures, quality of life, clinical or organizational practices, as well as on our living togetherness. By selecting issues for the preliminary analysis, the HTA process implicitly evaluates that certain issues are more relevant than others. Such an evaluation rests on the value attributed to the impacts of the drug or the technology being assessed. Eliciting the implicit value judgment involved requires providing justifications (or reasons) for excluding certain issues at the early step of the process.

The HTA guidelines of the Agency for Health Technology Assessment and Tariff System (AOTMiT, Poland) (The Agency for Health Technology Assessment and Tariff System, 2016) proposes, for the decision problem analysis (scoping step), the use of a PICOS scheme (Population, Intervention, Comparator, Outcomes and Study). The choice of a comparator is fundamental for HTA analysis because it will constitute the basis of its final evaluation. Basically, the drug or technology to be evaluated will either be better, equal or worse than the comparator. Since drugs or technologies may have multiple impacts, determin- 
ing that one comparator is better than another requires an explanation. In HTA, clinical effectiveness usually guides the choice of the comparator, but such a choice can limit the taking into consideration of other impacts. For instance, certain drugs could be less efficient for a given health problem when compared to others, but they may have fewer side effects. If the choice of the comparator is to uncover the best clinically efficient drug or technology, this could constrain comparisons such as those of the side effects and their impact on the patient.

The AOTMiT HTA guidelines (The Agency for Health Technology Assessment and Tariff System, 2016) highlight the importance of the scoping step designation by qualifying it as the "decision problem analysis". "It is recommended to prepare decision problem analysis as a separate document, which must be a common starting point for the analysis of each health technology associated with a particular health problem. The directions and scope of the analyses and methods, including the rules for the selection of data and information contained in the HTA report, must be presented in the decision problem document" (The Agency for Health Technology Assessment and Tariff System, 2016). There are two possible versions of this decision problematic that need to be considered. The first is the policy question (Table 1 Step 6), which refers to the very scope of the decision that has to be taken by the decision makers. The framing of the policy question clarifies the aim of the HTA in light of the conclusions of the final report that should guide the final value judgment on the actions to be undertaken. The social aim of HTA is to guide decision makers in their difficult task of making choices that have multiple impacts on individuals and society. The evaluation of the relevance of an HTA report necessarily implies answering the question: "How does this report help to answer the policy question?"

The second, which is the fundamental goal of the scoping step, is to formulate the research question (Table 1 Step 7) and choose the type of analyses and methods that will gather the information needed to answer it. The goal of this preliminary analysis is to give reasons that justify why the research question, as formulated, is the best to answer the decisional question. The evaluation of the research question will mobilize at least three criteria: its relevance to the agency's mandate, its relevance to the policy question and its relevance to the impact analysis. Once the value of the research question is clearly elicited, it can effectively guide the gathering of data, its interpretation and the writing of the final report.

The data gathering strategy, as well as data gathering itself (Table 1 Steps 8 and 9, respectively), involves many methodological decisions that will determine the overall value of the information gathered and its relevance to the research question. HTA guidelines such as the EUnetHTA Core Model (European Network for Health Technology Assessment (EUnetHTA), 2016) propose specific procedures for each type of analysis of a drug or technology. Each analysis focuses on the convergence of certain impacts of the drug or technology to be assessed. They are: safety, clinical effectiveness, costs and economic evaluations, ethical analysis, organizational aspects, patients and social aspects as well as legal 
aspects. For each analysis, precision is given on the scope of the analysis (i.e. its description), its methodology and the assessment elements. Safety and clinical effectiveness usually share the same scientific methodology, and this is why they are grouped together in the AOTMiT HTA guidelines as clinical analyses (The Agency for Health Technology Assessment and Tariff System, 2016). But various methodologies for cost and economic evaluation differ from one another. This also applies to ethical analysis, as well as the gathering of information on the implied organizational, legal and social aspects. At the end of the analysis, the value of the results can only be elicited by understanding the rationale behind the multiple value judgments implied in the methodological choices for each analysis.

Since its beginnings, the HTA process has been guided by an evidence-based procedure. The title of the 2018 Annual Health Technology Assessment international (HTAi) meeting: "Strengthening the Evidence-to-Action Connection" was significant in that regard. But what is evident for some people may not be to others. To show that something is evident requires giving proofs that justify such judgment. Evaluating the quality of the evidence (Table 1 Step 10) is therefore central to the HTA process. The quality of the evidence is evaluated differently, since each type of analysis possesses its own different methodology. In fact, the quality standard of evidence for clinical trial analysis cannot be transferred to cost and economic evaluations or to ethical analyses. Randomized controlled trials research is considered as high-quality evidence in clinical trial analyses but this cannot be systematically transferred to the other types of analyses.

Drafting an HTA report entails many decisions involving the choice of the report's argument structure and that of the information to be included therein. The argument structure of the report involves decision concerning five steps (see Table 1 Steps 11 to 15). The distinction between assessment and appraisal proposes a way of reporting the research findings as reported by Martin and colleagues: "Following Blanquaert \& Caron the process of HTA can be described as a combination of two phases: 1) assessment, which includes epidemiological studies, the collection of all available scientific information (e.g., literature review, cost-effectiveness analyses) and then a subsequent analysis and synthesis; and 2) appraisal, in which contextualised studies are conducted and recommendations made" (Martin et al., 2011). In this scheme, the report's structure is based on a distinction between "scientific information" and "contextualized studies". The scientific information is usually synthesized according to the epidemiological studies' quality of proof and the cost-effectiveness analyses. However, in this scheme, it is not clear how the results of contextualized studies should be presented. Finally, since recommendations are a part of the appraisal phase, the assessment phase's results should be integrated with those of contextual studies in the recommendations according to this scheme (Martin et al., 2011).

Not every HTA report includes recommendations and many reports end with a conclusion. This is often related to the governance structure (Table 1 Step 1) of the HTA agency. The decisions implied by choosing to give information or 
not in the conclusion of an HTA report are guided implicitly by a value judgment on the conclusions' relevance to decision makers. Should the conclusion answer only the research question (Table 1 Step 7) or both the policy- and the research-question (Table 1 Steps 6 and 7, respectively)? When the conclusions are limited to the research question, they will focus essentially on the results' presentation and evaluation obtained to answer the research question. Steps 11 to 14 (Table 1) will then be oriented on the validity of the results presented. The conclusion of a report answering not only the research question, but the policy question as well, requires the information gathered in the conclusion to be further evaluated. Policy questions are embedded in the daily transactions of governmental or hospital decision makers. It is difficult to answer policy questions without contextual studies on the impacts of a given decision on different professional health practices and services. In order to answer policy questions, it is therefore required to combine all types of information gathered during this process.

Combining all types of information requires an adjustment, in the conclusion, of the evidence-based paradigm since such requirement is rarely met in contextual studies. The evidence-based paradigm advocates for a "rational decision-making" model, whereby the best decision can only be grounded into validated and proven information. This model assumes, however, that decision-making does not involve value judgments but only facts. Furthermore, what happens when the information gathered cannot be considered as evidence-based? Bearing in mind that policy questions must be answered anyway, how can HTA reports guide decision makers when clear-cut evidence is not available?

When recommendations (Table 1 Step 15) are made in HTA reports, they clearly engage in a value judgment's evaluation procedure. To recommend something means to advise someone on the best course of action to be taken in a particular context. The validity of the recommendation thus rests on the value judgment that attributes a value to such course of action in this context. The evaluation of this course of action requires weighting it against the different evaluations from alternative courses of action. Eliciting value judgments at the step of the recommendation can only be achieved by integrating all the information from Steps 11 to 14 (Table 1) in a final evaluation of the findings. If the reasons justifying the recommendation are not clearly expressed in the report, they may probably be judged as arbitrary or at least as lacking reasonable grounds.

Reviewing of the HTA report (Table 1 Step 16) is another procedure aimed to confirm its validity. In any reviewing process, the choice of reviewers will also involve value judgments such as: is this reviewer the best? The expertise of a given individual will usually warrant such choice, but other contextual considerations will also often be considered. If a reviewer is only chosen based on his or her specific expertise, their evaluation might be limited to only one aspect of the report. Deciding on how to incorporate the reviewers' commentary in the final report (Table 1 Step 17) requires evaluating the relevance of their commentary. 
On what grounds specific commentaries will be rejected while others be considered? Furthermore, does such procedure include a dialogue with the reviewers and on how their commentary are being dealt with?

The decisions involved in the dissemination of the report (Table 1 Step 18) are also value-laden. Whom is the report addressed to? Which type of information is transferred in the report? The findings of an HTA pertain to many stakeholders. The dissemination strategy depends on the importance of the information for the different stakeholders, as well as its relevance. In certain cases, a summary of the full report can be intended for specific stakeholders, highlighting the elements relevant to their concerns.

\section{Conclusion}

In the HTA literature, two different ways of integrating ethics into the HTA process have been reported. One concerns the ethical analysis where ethical issues are identified, analyzed or evaluated, while the other aims to elicit the implicit value judgments involved in the HTA decision-making process. Research in this latter field requires a philosophical analysis of value, value judgments and decision-making. The HTA process, based on scientific evidence, proposes a rational decision-making approach where values are not considered and where only proven evidence should be taken into account. A sociological analysis reveals the dynamic of "evaluating facts" and "facting evaluations" and how different types of values identified in social practices could influence the decision-making process in HTA. Neither of these approaches clarifies the nature of values and their role in decision-making. We propose an alternative approach based on a decision-making paradigm elaborated in applied ethics where value judgments are an essential part of a reasonable decision in a particular context.

To operationalize this approach, we elicited, from a systematic review of HTA literature, eighteen steps in the HTA process and twenty-three implicit value judgments involved therein and their criteria. Since the mandate of HTA agencies across the world are not identical, the decision-making steps inherent to each mandate may differ. But the core of the evaluation remains. What is the relevant information that is needed to help decision makers in their difficult choices regarding drugs and health technologies? What is the validity of the information gathered? What are the best conclusions that can be drawn from these different analyses? How can these conclusions provide grounds for the value judgment imbedded in the recommendations? What is the relevance of the HTA findings for different stakeholders?

Eliciting the value-ladenness of the HTA process by linking the value judgments in each decision-making step provides focus on the crucial aspects that guide the entire HTA process. Integrating ethics into HTA by eliciting value judgments (evaluations) helps to understand that the ultimate aim of guiding decision-makers can ideally be reached by making recommendations based on evaluations (value judgments), which are in turn grounded on the systematic application of criteria based on empirical data. In this decision-making perspec- 
tive, judgment of facts and judgment of values are intertwined throughout the entire HTA process from the determination of the HTA agency's mandate to the final dissemination of the results.

This study clarifies the requisites to attain the social expectations for more transparency not only in the HTA process but in any decision-making process. Eliciting value judgments, their criteria and the factual judgments relating values and facts is the first operation required before the prioritizing of the conflicting value judgments in the decision-making process and each step should be justified on reasonable grounds for more transparency.

\section{Acknowledgements}

The authors wish to thank Ms. Louise Corbeil for editorial work on the manuscript.

\section{Funding}

This work was supported by the research grant from the Canadian Institutes of Health Research (CIHR grant number 142187 awarded to JP). The funding agency did not have any involvement in data collection, analysis and interpretation, as well as in the writing of this manuscript.

\section{Authors' Contributions}

All authors contributed to the study design. GAL, JP, JPB and MP reviewed the literature and extracted the citations. The HTA professionals (SKB, CAB, PD) helped to categorize the various steps. GAL, JP and HG drafted the text of this article. $\mathrm{PD}, \mathrm{SKB}, \mathrm{CAB}, \mathrm{CED}, \mathrm{JPB}, \mathrm{MP}$ and $\mathrm{LB}$ critically revised the text of this article. All authors read and approved the final version of this manuscript.

\section{Statement}

We the authors, listed below, attest that 1) each author contributed to the conception, design or analysis and the interpretation of data, including the writing of this paper; 2) each contributor has approved the version being submitted; and 3) that the content has not been published nor is being considered for publication elsewhere.

\section{Conflicts of Interest}

The authors declare that they have no competing interests.

\section{References}

Bellemare, C. A., Dagenais, P., Bédard, S. K., Béland, J. P., Bernier, L., Daniel, C. É., Gagnon, H., Legault, G. A., Parent, M., \& Patenaude, J. (2018). Ethics in Health Technology Assessment: A Systematic Review. International Journal of Technology Assessment in Health Care, 34, 447-457. https://doi.org/10.1017/S0266462318000508

Bellemare, C. A., Fisette, J., Poder, T. J., Bédard, S., \& Dagenais, P. (2017). The Health 
Technology Assessment Unit of the Centre Hospitalier universitaire de Sherbrooke (Canada). In L. Sampietro-Colom, \& J. Martin (Eds.), Hospital-Based Health Technology Assessment: The Next Frontier for Health Technology Assessment (pp. 185-200). Berlin: Springer International Publishing. https://doi.org/10.1007/978-3-319-39205-9 16

Bernier, L., Legault, G. A., Daniel, C. É., K.-Bédard, S., Béland, J. P., Bellemare, C. A., Dagenais, P., Gagnon, H., Parent, M., \& Patenaude, J. (2020). Legal Governance in HTA: Environment, Health and Safety Issues/Ethical, Legal and Social Issues (EHSI/ELSI), the Ongoing Debate. Canadian Journal of Bioethics, 3, 83-92.

https://doi.org/10.7202/1070226ar

Burls, A., Caron, L., Cleret de Langavant, G., Dondorp, W., Harstall, C., Pathak-Sen, E., \& Hofmann, B. (2011). Tackling Ethical Issues in Health Technology Assessment: A Proposed Framework. International Journal of Technology Assessment in Health Care, 27, 230-237. https://doi.org/10.1017/S0266462311000250

Busse, R., Orvain, J., Velasco, M., Perleth, M., Drummond, M., Grtner, F., Jørgensen, T., Jovell, A., Malone, J., Rüther, A., \& Wild, C. (2002). Best Practice in Undertaking and Reporting Health Technology Assessments: Working Group 4 Report. International Journal of Technology Assessment in Health Care, 18, 361-422. https://doi.org/10.1017/S0266462302000284

DeJean, D., Giacomini, M., Schwartz, L., \& Miller, F. A. (2009). Ethics in Canadian Health Technology Assessment: A Descriptive Review. International Journal of Technology Assessment in Health Care, 25, 463-469.

https://doi.org/10.1017/S0266462309990390

Duthie, K., \& Bond, K. (2011). Improving Ethics Analysis in Health Technology Assessment. International Journal of Technology Assessment in Health Care, 27, 64-70. https://doi.org/10.1017/S0266462310001303

Éditeur officiel du Québec (2018). Loi sur l'Institut national d'excellence en santé et en services sociaux. Québec.

European Network for Health Technology Assessment (EUnetHTA) (2016). Joint Action 2, Work Package 8: HTA Core Model, v. 3.

Fletcher, J. F. (1966). Situation Ethics: The New Morality. Philadelphia, PA: Westminster Press.

Hofmann, B. (2013). Health Technology Assessment-Science or Art? GMS Health Technology Assessment, 9, 1-8.

Hofmann, B. M. (2008). Why Ethics Should Be Part of Health Technology Assessment. International Journal of Technology Assessment in Health Care, 24, 423-429. https://doi.org/10.1017/S0266462308080550

Hofmann, B. M., Bond, K., \& Sandman, L. (2018). Evaluation Facts and Facting Evaluation: On the Fact-Value Relationship in HTA. Journal of Evaluation in Clinical Practice, 24, 957-965. https://doi.org/10.1111/jep.12920

Hofmann, B., Cleemput, I., Bond, K., Krones, T., Droste, S., Sacchini, D., \& Oortwijn, W. (2014a). Revealing and Acknowledging Value Judgments in Health Technology Assessment. International Journal of Technology Assessment in Health Care, 30, 579-586. https://doi.org/10.1017/S0266462314000671

Hofmann, B., Droste, S., Oortwijn, W., Cleemput, I., \& Sacchini, D. (2014b). Harmonization of Ethics in Health Technology Assessment: A Revision of the Socratic Approach. International Journal of Technology Assessment in Health Care, 30, 3-9.

https://doi.org/10.1017/S0266462313000688

Hofmann, B., Oortwijn, W., Bakke Lysdahl, K., Refolo, P., Sacchini, D., van der Wilt, G. 
J., \& Gerhardus, A. (2015). Integrating Ethics in Health Technology Assessment: Many Ways to Rome. International Journal of Technology Assessment in Health Care, 31, 131-137. https://doi.org/10.1017/S0266462315000276

INAHTA (2005). INAHTA's Working Group on Handling Ethical Issues. Final Report.

Kristensen, F., \& Sigmund, H. (2007). Health Technology Assessment Handbook. Copenhagen: Danish Centre for Health Technology Assessment, National Board of Health.

Legault, G. A. (1999). Professionnalisme et délibération éthique. Presses de l'université du Québec, Sainte Foy, QC, Canada. https://doi.org/10.2307/j.ctv5j01t2

Legault, G. A., Béland, J. P., Parent, M., K.-Bédard, S., Bellemare, C. A., Bernier, L., Dagenais, P., Daniel, C. É., Gagnon, H., \& Patenaude, J. (2019). Ethical Evaluation in Health Technology Assessment: A Challenge for Applied Philosophy. Open Journal of Philosophy, 9, 331-351. https://doi.org/10.4236/ojpp.2019.93022

Legault, G. A., Verchères, C., \& Patenaude, J. (2018). Support for the Development of Technological Innovations: Promoting Responsible Social Uses. Science and Engineering Ethics, 24, 529-549. https://doi.org/10.1007/s11948-017-9911-5

Legault, G.-A., K.-Bédard, S., Bellemare, C. A., Béland, J.-P., Bernier, L., Dagenais, P., Daniel, C.-É., Gagnon, H., Parent, M., \& Patenaude, J. (2018). Revisiting the Fact/Value Dichotomy: A Speech Act Approach to Improve the Integration of Ethics in Health Technology. Open Journal of Philosophy, 8, 578-593.

https://doi.org/10.4236/ojpp.2018.85042

Martin, C., Williams-Jones, B., \& de Ortúzar, M. G. (2011). Ethical Health Technology Assessment in Latin America: Lessons from Canada and Argentina. Acta Bioethica, 17, 225-236. https://doi.org/10.4067/S1726-569X2011000200009

Patenaude, J., Legault, G.-A., Bernier, L., Beauvais, J., Béland, J.-P., Boissy, P., Chenel, V., Daniel, C.-É., Genest, J., Poirier, M.-S., \& Tapin, D. (2015). Framework for the Analysis of Nanotechnologies' Impacts and Ethical Acceptability: Basis of an Interdisciplinary Approach to Assessing Novel Technologies. Science and Engineering Ethics, 21, 293-315. https://doi.org/10.1007/s11948-014-9543-y

Perelman, C. (1979). The New Rhetoric and the Humanities. Synthese Library (Studies in Epistemology, Logic, Methodology, and Philosophy of Science) Vol. 140, Dordrecht: Springer.

Rawlins, M. D. (2014). Evidence, Values, and Decision-Making. International Journal of Technology Assessment in Health Care, 30, 233-238.

https://doi.org/10.1017/S0266462314000154

Reuzel, R., Oortwijn, W., Decker, M., Clausen, C., Gallo, P., Grin, J., Grunwald, A., Hennen, L., van der Wilt, G. J., \& Yoshinaka, Y. (2004). Ethics and HTA: Some Lessons and Challenges for the Future. Poiesis \& Praxis, 2, 247-256.

https://doi.org/10.1007/s10202-003-0054-1

Saarni, S. I., Braunack-Mayer, A., Hofmann, B., \& van der Wilt, G. J. (2011). Different Methods for Ethical Analysis in Health Technology Assessment: An Empirical Study. International Journal of Technology Assessment in Health Care, 27, 305-312. https://doi.org/10.1017/S0266462311000444

Saarni, S. I., Hofmann, B., Lampe, K., Luhmann, D., Makela, M., Velasco-Garrido, M., \& Autti-Ramo, I. (2008). Ethical Analysis to Improve Decision-Making on Health Technologies. Bulletin of the World Health Organization, 86, 617-623.

https://doi.org/10.2471/BLT.08.051078

Sandman, L., \& Heintz, E. (2014). Assessment vs. Appraisal of Ethical Aspects of Health Technology Assessment: Can the Distinction Be Upheld? GMS Health Technology As- 
sessment, 10, Doc05.

Strech, D., \& Tilburt, J. (2008). Value Judgments in the Analysis and Synthesis of Evidence. Journal of Clinical Epidemiology, 61, 521-524. https://doi.org/10.1016/j.jclinepi.2008.01.001

ten Have, H. (2004). Ethical Perspectives on Health Technology Assessment. International Journal of Technology Assessment in Health Care, 20, 71-76. https://doi.org/10.1017/S0266462304000819

The Agency for Health Technology Assessment and Tariff System (2016). Health Technology Assessment Guidelines. Warsaw.

The National Institute for Health and Care Excellence (NICE) (2008). Social Value Judgments, Principles for the Development of NICE Guidance.

WHO-HTA (2017). WHO: Medical Devices. WWW Document. http://www.who.int/medical devices/assessment/en

\section{Abbreviation}

HTA: Health Technology Assessment 